\title{
Monitoramento ambiental em bordas de grandes reservatórios hidrelétricos
}

\author{
Caio L. M. Jerônimo, Igor G. de M. Cruz, Cláudio E. C. Campelo, Cláudio de \\ S. Baptista, Júlio H. Rocha, Murilo S. L. Pinto, Hugo F. de Figueirêdo \\ Departamento de Sistemas e Computação \\ Universidade Federal de Campina Grande (UFCG) - Campina Grande, PB - Brazil \\ \{caiolibanio, igorgomes, juliorocha\} @copin.ufcg.edu.br, \{campelo, \\ baptista\}@dsc.ufcg.edu.br, mspinto@chesf.gov.br, \\ hugo.figueiredo@ifpb.edu.br
}

\begin{abstract}
The economic development of Brazil, the search for improvements in the country's electrical infrastructure and new regulations in the electricity sector have made electric utilities seek new technical solutions that can help the environmental control process. This paper presents a solution to facilitate the monitoring of the concession areas of hydroelectric power plants to meet the requirements of new resolutions of the hydroelectric sector. Such regulations have influenced the way companies must acquire, maintain and report environmental and sociopatrimonial information about concession areas, to promote the appropriate use of available natural resources, the preservation of protected areas and greater control over properties that are located nearby.
\end{abstract}

Keywords: environmental management, monitoring hydroelectric reservoirs surroundings, geographic information systems.

Resumo. O desenvolvimento econômico do Brasil, a busca por melhorias na infra-estrutura elétrica do país e as novas regulamentações do setor elétrico, têm levado as concessionárias de energia elétrica a buscarem novas soluções técnicas que possam auxiliar o processo de controle ambiental. Este artigo apresenta uma solução para facilitar o monitoramento das áreas de concessão de usinas hidrelétricas para atender aos requisitos das novas resoluções do setor hidrelétrico. Tais regulamentações têm influenciado o modo como as empresas devem adquirir, manter e reportar informações ambientais e sociopatrimoniais acerca das áreas de concessão, de forma a promover um melhor uso dos recursos naturais disponíveis, a preservação de áreas protegidas e um maior controle sobre as propriedades localizadas em áreas próximas.

Palavras-chave: gestão ambiental, monitoramento de bordas de reservatórios, sistemas de informação geográfica.

\section{Introdução}

O panorama mundial está mudando rapidamente, por motivos ligados a três das grandes preocupações da humanidade nesse início de século: meio ambiente, energia e economia 
global (VICHI e MANSOR, 2009). O Brasil possui um enorme potencial hídrico e, com isso, possui grande responsabilidade no setor de energia. Com a expansão econômica mundial, a procura por energia no país tem sido cada vez maior. Segundo a Resolução Normativa $n^{0} 501$ (BRASIL, 2012), o empreendedor, no âmbito do procedimento de licenciamento ambiental, deve elaborar o plano ambiental de conservação e uso do entorno de reservatório artificial em conformidade com o termo de referência expedido pelo órgão ambiental competente, para os reservatórios artificiais destinados à geração de energia e abastecimento público. Assim, o cumprimento desse plano ambiental é algo de extrema importância para as concessionárias de energia elétrica, uma vez que seu descumprimento impõe a aplicação de multas.

De acordo com MATTOS et al. (2007), Áreas de Preservação Permanente (APPs), dentre os tipos de florestas de proteção, possuem destaque pela sua importância na prestação de serviços ambientais para toda a sociedade. As APPs são áreas protegidas pelo Código Florestal Brasileiro, cobertas ou não por vegetação nativa com a função ambiental de preservar os recursos hídricos, a paisagem, dentre outros. Nestas áreas, os recursos naturais não podem ser explorados. Essas áreas são localizadas, por exemplo, em margens de rios, encostas e em topos de morros.

Assim, percebe-se a importância de um bom gerenciamento das atividades humanas e ambientais nas APPs e de um melhor monitoramento de possíveis impactos ambientais causados nessas regiões. Porém, esta atividade de monitoramento é bastante desafiadora, especialmente devido ao tamanho das áreas em torno dos reservatórios. Por exemplo, o reservatório de Sobradinho, com $4.214 \mathrm{~km}^{2}$, está entre os maiores espelhos d'água artificiais da terra (GODINHO e GODINHO, 2003). Desta forma, o apoio tecnológico em situações como essa se torna essencial.

Este artigo apresenta uma solução para o monitoramento das áreas do entorno de reservatórios, que inclui um mecanismo para auxiliar a coleta de dados ambientais e sociopatrimoniais, bem como um mecanismo para identificação e gestão de irregularidades na exploração das áreas protegidas. A solução proposta combina o uso de um aplicativo móvel e um sistema Web e oferece recursos para obtenção e manipulação de informações georreferenciadas e multimídia, auxiliando substancialmente o processo de tomada de decisão, visando o cumprimento das regulamentações e a preservação ambiental.

\section{Controle de Irregularidades nas APPs}

As APPs devem ser preservadas com o objetivo de cumprir sua função ambiental de preservar os recursos hídricos, proteger o solo, promover o bem-estar público, dentre outras. O Código Florestal tenta assegurar esta função, ilegalizando o uso dessas áreas para culturas e urbanizações. Por exemplo, conforme discutido por MONTEBELO et al. (2005), o uso de culturas anuais nas APPs podem causar derramamento de resíduos tóxicos nos rios, enquanto a pecuária excessiva pode gerar a degradação da pastagem.

Há uma variedade de irregularidades que podem ser observadas nas APPs. Por exemplo, conforme apontado por PINTO et al. (2005), na bacia hidrográfica do Ribeirão Santa Cruz, cerca de $37,5 \%$ de sua área deveriam estar ocupados com vegetação nativa, porém somente $25,74 \%$ permanecem dessa forma. 
Com o monitoramento adequado das ocorrências dessas irregularidades, é possível gerar uma base de dados referente aos incidentes ambientais observados nas margens dos reservatórios, de forma a viabilizar medidas preventivas e corretivas, favorecendo assim a manutenção e preservação ambiental dessas áreas. O controle de irregularidades deve ser feito rotineiramente pela empresa responsável ou, em casos especiais, na presença de denúncias realizadas por moradores das regiões ou órgãos externos à empresa.

A solução desenvolvida permite a identificação e registro de doze tipos de ocorrências:

- Abalroamento, Incêndio, Naufrágio de Embarcações: ocorrência relacionada a possíveis incidentes envolvendo embarcações que se locomovem nas águas dos reservatórios. Este tipo de incidente pode acarretar graves consequências como, por exemplo, risco à vida das pessoas envolvidas e à vida marinha da região;

- Acidentes com Produto Químico Perigoso: refere-se a eventos de derramamento de produtos tóxicos nos leitos dos reservatórios, podendo causar grandes impactos ao meio natural pertencente às Áreas de Preservação Permanente;

- Queimada e Incêndio em Vegetações: este tipo de ocorrência visa o monitoramento e a preservação de toda a fauna e flora contra possíveis queimadas e incêndios causados naturalmente ou provocados pelo homem nas matas próximas aos reservatórios.

- Afogamentos: são possíveis eventos de afogamento nos leitos dos reservatórios. Com esta ocorrência, é possível fazer o levantamento de áreas com um alto grau de incidentes deste tipo, a fim de evitar que novos acidentes ocorram;

- Mortandade de Peixes: têm como objetivo registrar a mortandade de peixes ocorridas nas águas dos reservatórios, relacionando os tipos de peixe envolvidos e as possíveis causas da ocorrência;

- Contaminação por Efluentes Líquidos: ocorrência que registra contaminações por efluentes líquidos próximos aos reservatórios, de modo a auxiliar na preservação e manutenção de toda a vida aquática envolvida;

- Contaminação por Resíduos Sólidos: registra eventos de contaminação por dejetos sólidos, com o objetivo de proteger a fauna e flora das APPs;

- Deslizamento de Taludes Marginais: refere-se a deslizamentos e erosões ocorridas nas margens do reservatório, que representam um grave problema ambiental, já que podem levar a uma degradação das margens dos reservatórios e de toda a mata ciliar;

- Proliferação de Macrófitas Aquáticas: ocorrência que registra a proliferação desordenada de macrófitas aquáticas. O desenvolvimento excessivo deste tipo de planta pode trazer riscos para a vida marinha e aos leitos dos reservatórios;

- Retirada de Madeira em Áreas Remanescentes ou APP: permite o levantamento de dados sobre a retirada irregular de madeira nas APPs, possibilitando medida preventivas melhores e mais rápidas para esse tipo de situação.

- Uso Irregular das Margens e Ocupação Irregular de Terras do Empreendedor: registra o uso inadequado das margens dos reservatórios, bem como possíveis invasões às áreas de propriedade da empresa. Esta ocorrência visa evitar o uso indevido das áreas de proteção, o que pode causar danos ao meio ambiente envolvido; 
- Inundação: tipo de ocorrência referente a inundações ocorridas nas áreas em torno do reservatórios, que podem gerar danos ambientais ou aos ocupantes dessas áreas.

\section{Visão Geral da Solução}

A solução desenvolvida tem o objetivo de facilitar o gerenciamento das APPs por meio do auxílio computacional no controle de ocorrências, monitoramento sociopatrimonial e socioambiental e é composto por dois módulos: módulo móvel e módulo Web.

Na Figura 1, ilustra-se uma visão geral da solução. Os dados georreferenciados e multimídia são coletados em campo utilizando o módulo móvel e, posteriormente, estes são transferidos para o módulo Web. Neste, os usuários podem visualizar os dados (e.g., registros de ocorrências) com auxílio de um mapa interativo, gerar relatórios e realizar análises para apoiar a tomada de decisão. Este módulo contém um Sistema de Informação Geográfico (SIG), independente de plataforma, que se destina a usuários do setor tático e estratégico da empresa, responsáveis por analisar e gerenciar as áreas das APPs. Segundo JUNIOR et al. (2010), esse tipo de sistema ajuda no monitoramento, controle e fiscalização ambiental por meio de diagnósticos feitos mediante a sobreposição de informações espaciais da bacia hidrográfica. O sistema ainda oferece um módulo de análise de imagens de satélite para detecção automática de mudanças no uso do solo, visando facilitar a identificação de irregularidades e o melhor direcionamento das vistorias realizadas pessoalmente em campo.

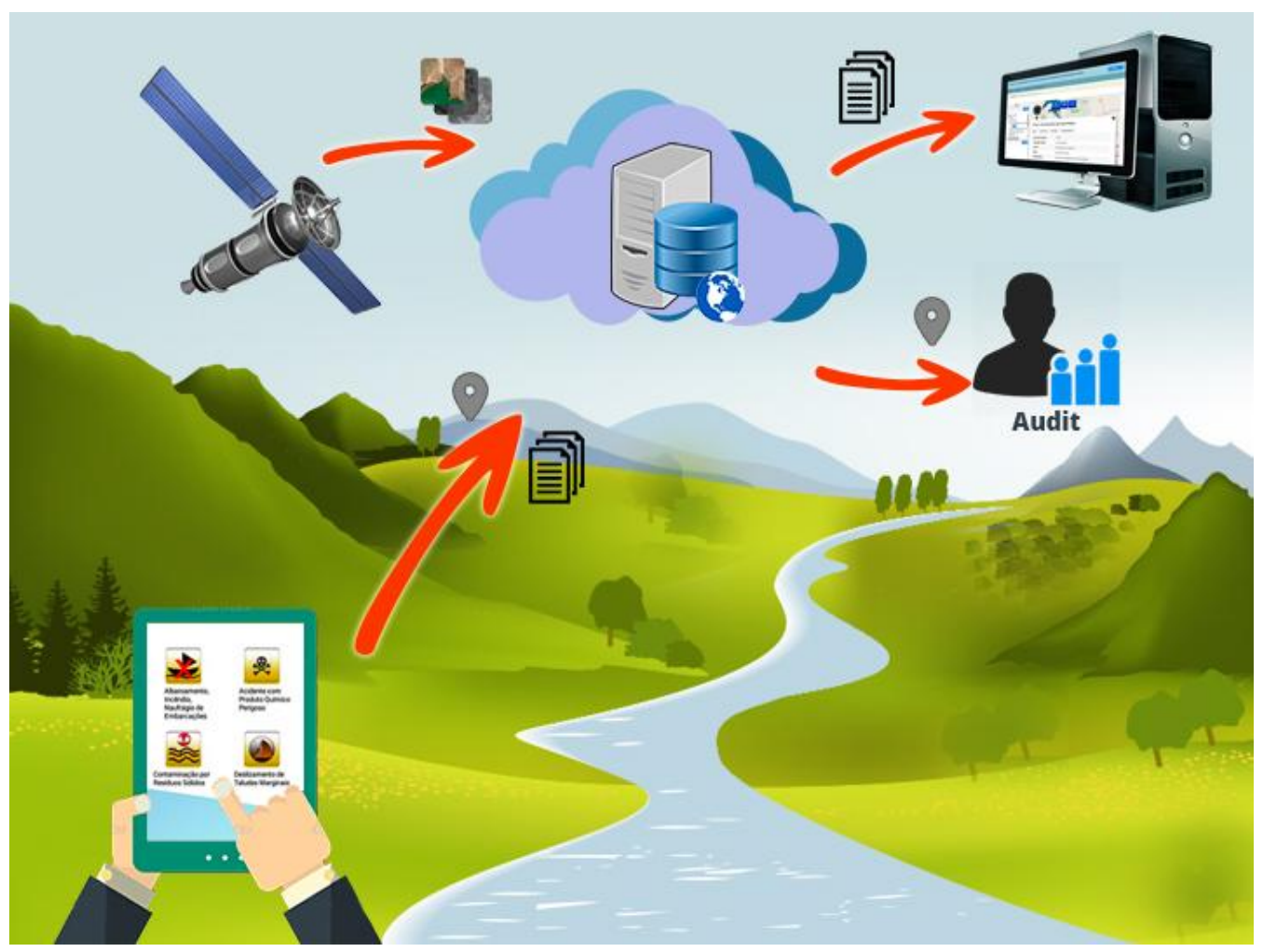

Figura 1 - Interação entre usuários e os módulos

Além disso, como todo o processo organizacional é agora realizado por meio eletrônico, é possível armazenar dados para fins de auditoria, o que permite um controle 
sobre todas as mudanças realizadas nos dados, possibilitando uma confirmação da autenticidade das informações, que podem ser obtidas tanto por pessoal interno à concessionária quanto por empresas terceirizadas. A visualização das mudanças por meio de auditoria é feito por uma interface simples e intuitiva, a qual apresenta as inserções e modificações dos dados em uma linha do tempo, facilitando $o$ gerenciamento destas informações como pode ser visto na Figura 2.

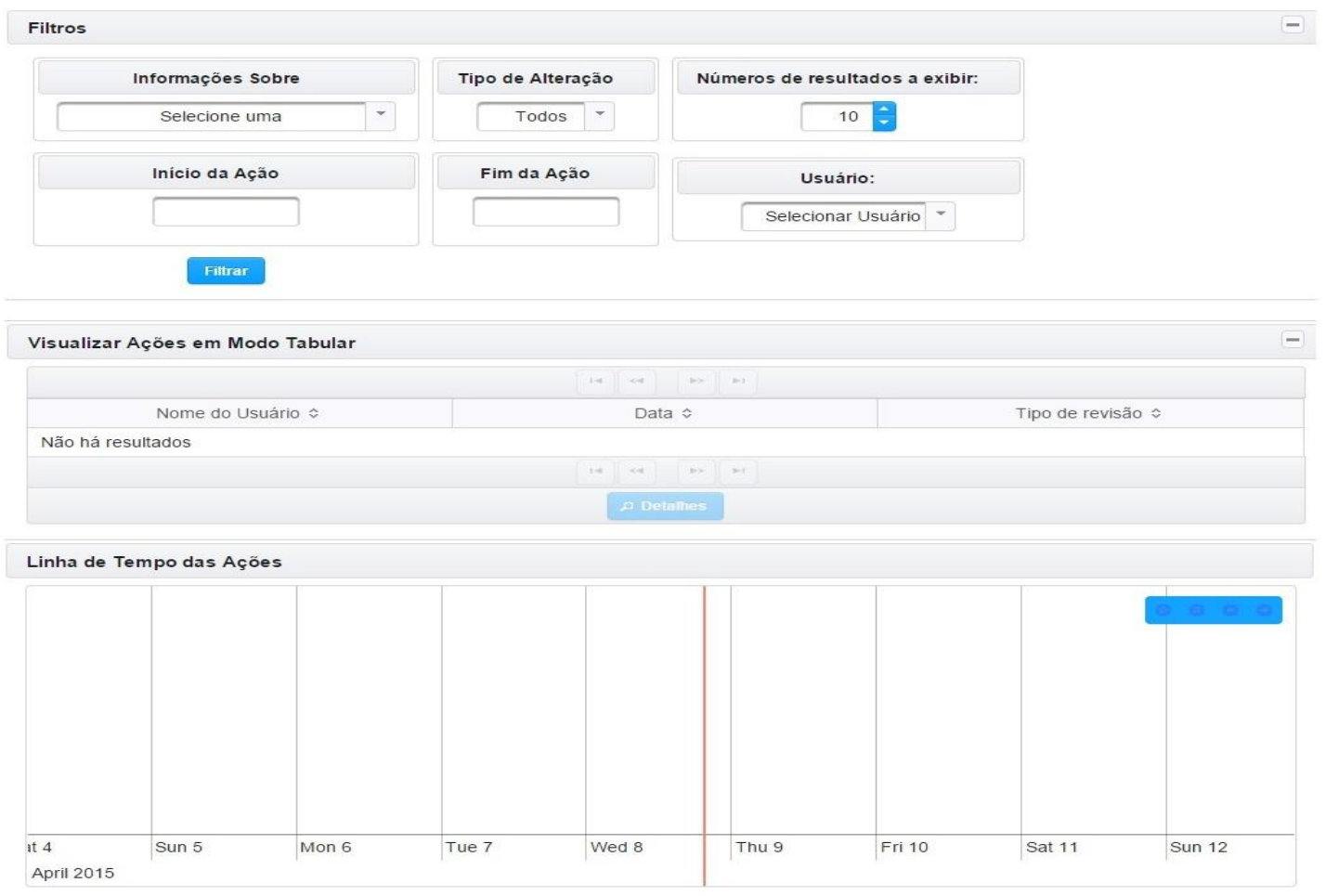

Figura 2 - Sistema de auditoria

O módulo móvel (figura 3), desenvolvido para tablets com sistema operacional Android, é utilizado em campo para realizar vistorias, monitorar ocorrências e cadastrar informações sociopatrimoniais. Este aplicativo permite georreferenciar todas as informações que são coletadas por ele, com isto, torna-se possível uma análise precisa do local em que as irregularidades estejam ocorrendo nas áreas de preservação. Após a devida coleta dos dados, é possível que estes sejam exportados (no formato JSON) e enviados, via e-mail por exemplo, para um reponsável da empresa em questão, que por meio do sistema Web, será capaz de importar os dados e realizar uma análise mais completa das informações obtidas em campo. 


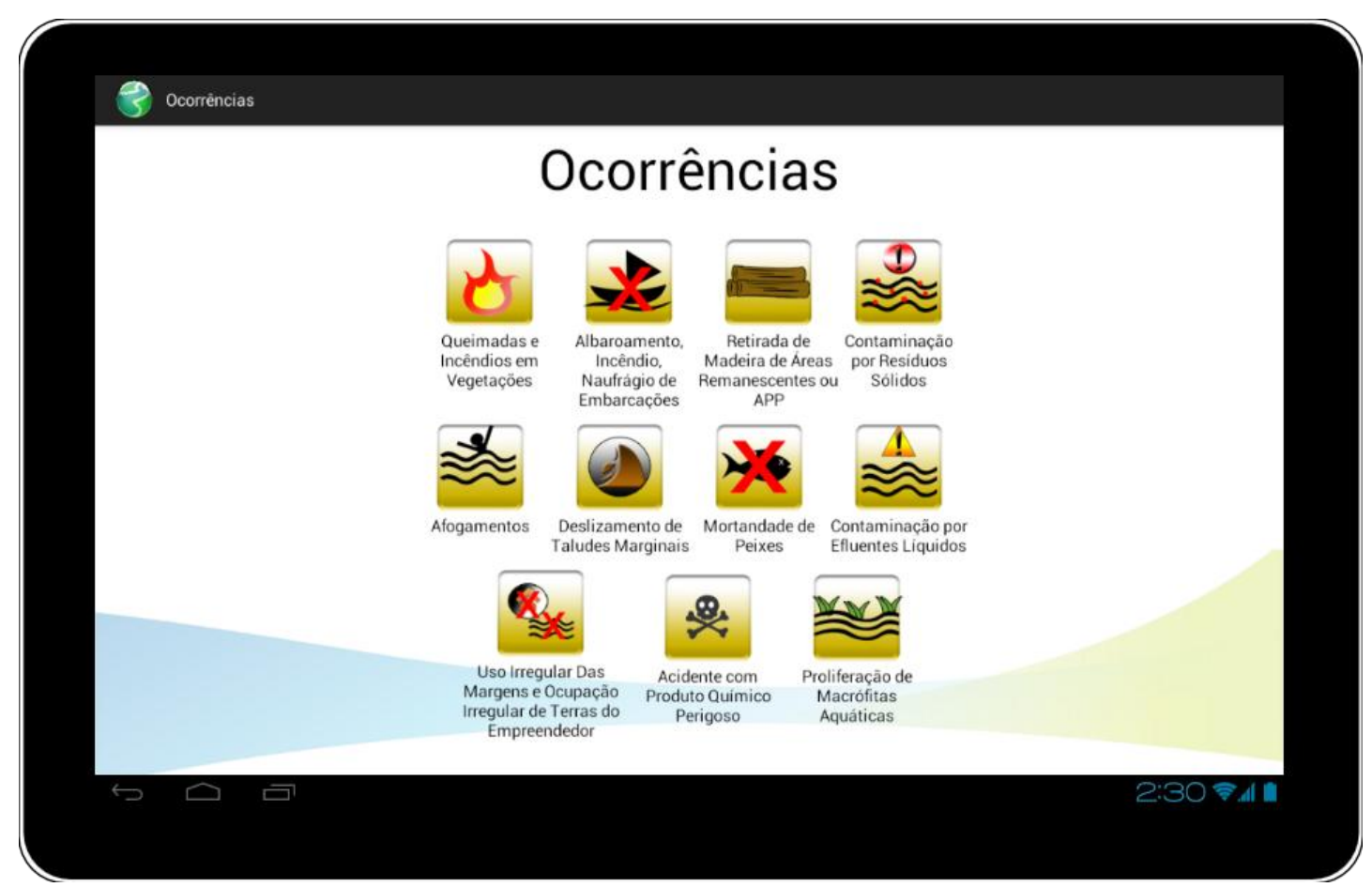

Figura 3 - Cadastro de ocorrências no módulo móvel do sistema

\section{Mapas Temáticos}

Um destaque disponibilizado pelo módulo Web é a possibilidade de visualização e manipulação de mapas temáticos, através dos quais é possível analisar com mais detalhes as regiões que margeiam os reservatórios. Por meio dos mapas temáticos, é possível obter informações mais precisas e de forma imediata sobre a localização e extensão de determinadas regiões de interesse, facilitando a visualização das informações presentes em um contexto geográfico.

Como mostrado na Figura 4, para auxiliar na gestão ambiental das bordas dos reservatórios, o usuário pode manipular e adicionar diferentes camadas de mapas. Essas camadas podem ser oferecidas pelo sistema (APPs, reservatórios, propriedades, vegetações, dentre outras) ou por meio de serviços externos como Geoserver e Arcgis. Além disso, o usuário dispõe de vários recursos como: medição de distância entre pontos no mapa, cálculo de área sobre regiões selecionadas, busca e visualização de ocorrências e reservatórios cadastrados, dentre outros. O uso de mapas digitais favorece substancialmente a detecção de áreas degradadas ou que estejam em processo de degradação e auxiliam significativamente na gestão de ocorrências. Por exemplo, é possível calcular as distâncias entre um reservatório e uma possível ocorrência que esteja acontecendo em suas proximidades, a fim de avaliar os riscos que esta pode trazer as regiões em torno do reservatório. 


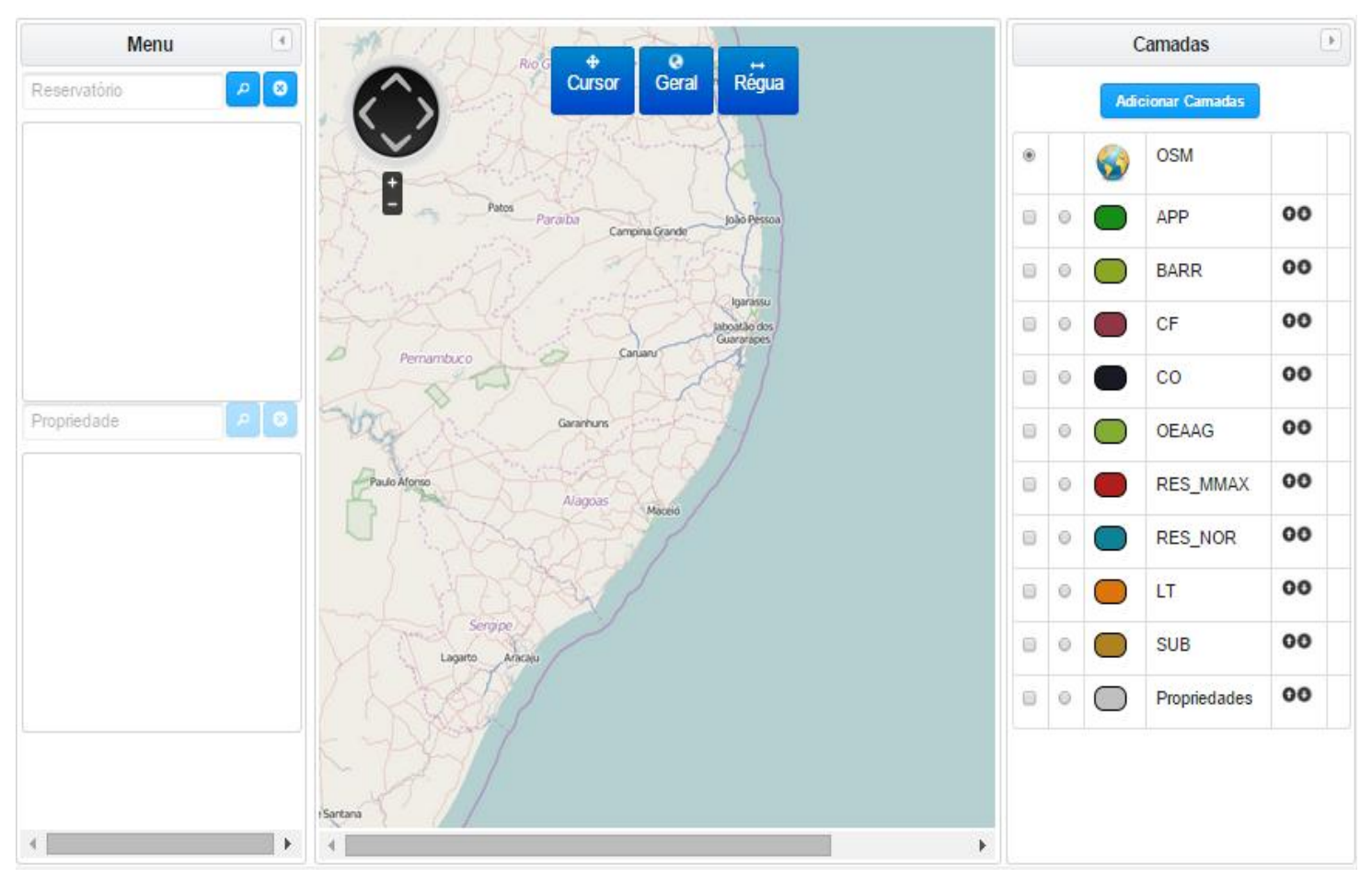

Figura 4 - Mapas temáticos

\section{Imagens de satélite}

Segundo MASCARENHAS et al. (2009), a degradação do meio ambiente, o uso não sustentável dos recursos naturais e as mudanças climáticas, atualmente, têm sido grandes preocupações dos cientistas no mundo inteiro. Assim, esses temas necessitam cada vez mais de melhores técnicas de monitoramento sistemático e sinóptico. Logo, junto aos grandes avanços tecnológicos vivenciados nas últimas décadas, foram desenvolvidos satélites de monitoramento terrestre-ambiental que possibilitam em escala global, regional ou local, a coleta de dados (quantitativos e qualitativos) sobre o grau de degradação ambiental, níveis de poluição da água e da atmosfera e diversos outros fatores.

Sistemas de satélite e técnicas de analise de imagens têm evoluído, nos últimos anos, com objetivo de apoiar a gestão de grandes catástrofes naturais. Atualmente, houve uma melhora substancial na disponibilidade, quantidade, pontualidade $\mathrm{e}$ confiabilidade dessas imagens em relação a dez anos atrás (VOIGT et al., 2007).

A partir disso, para um melhor monitoramento das áreas dos entornos dos reservatórios, foi desenvolvido um módulo de gerenciamento de imagens de satélite, no qual o usuário pode adicionar imagens de satélite georreferenciadas referentes às APPs. Assim, dado um conjunto de imagens de uma mesma área, obtidas em instantes de tempo diferentes, este módulo permite a detecção automática de mudanças no uso do solo, que podem sugerir invasões ilegais e/ou possíveis danos nas Áreas de Preservação Permanente no entorno dos reservatórios.

A Figura 5 apresenta as informações que podem ser vinculadas a uma imagem de satélite: tipo (imagem, lidar ou ortofoto), data, descrição, coordenadas geográficas de uma determinada área selecionada e o arquivo da imagem. 


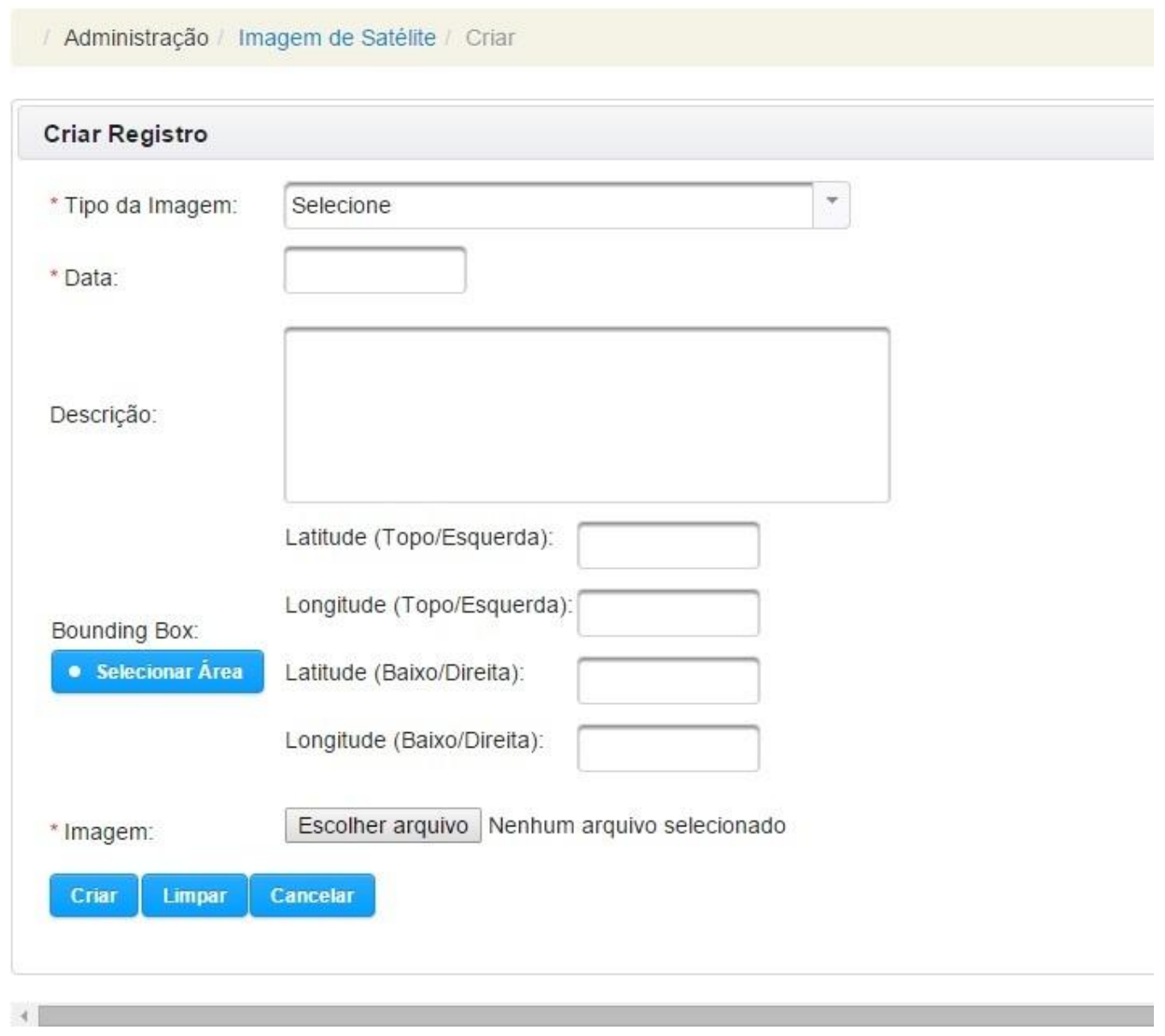

Figura 5 - Imagens de satélite

\section{Conclusão}

O avanço tecnológico tem se mostrado bastante útil para a gestão e preservação ambiental, favorecendo empresas que possuem esse tipo de obrigação. Nesse contexto, o sistema apresentado disponibiliza ferramentas essenciais para o auxílio, gerência e manutenção de dados relativos ao meio ambiente das áreas dos entornos dos reservatórios, auxiliando na correta gestão ambiental dessas áreas e facilitando a tomada de decisão. Dessa forma, as concessionárias de energia elétrica podem atender de forma mais eficaz às implicações legais de manutenção ambiental das áreas de concessão, favorecendo assim a preservação do meio natural que margeia os grandes reservatórios e reduzindo possíveis impactos ambientais que possam ocorrer sem o correto gerenciamento e manutenção destas regiões.

\section{Agradecimentos}

Os autores agradecem a ANEEL por financiar este projeto de P\&D+I sob o contrato de número ANEEL 0048-1119/2012. 


\section{Referências}

BRASIL. Agência Nacional de Energia Elétrica - ANEEL. Resolução Normativa $n^{\circ}$ 501, de 24 de julho de 2012. Disponível em: www.aneel.gov.br/cedoc/ren2012501.pdf. Último acesso: 13/03/2015.

BRASIL. Resolução CONAMA n ${ }^{\circ}$ 302, de 20 de março de 2002. Disponível em: www.mma.gov.br/port/conama/legislacao/CONAMA_RES_CONS_2002_302.pdf. Último acesso: 13/03/2015.

GODINHO, H. P. e GODINHO, A. L. Águas, peixes e pescadores do São Francisco das Minas Gerais. Belo Horizonte: PUC Minas, p. 16, 2003. Último acesso: 08/04/2015.

JUNIOR, R.F.V. et al. Determinação das Áreas de Preservação Permanente na Bacia Hidrográfica do Rio Uberaba - MG, utilizando o Sistema de Informação Geográfica - SIG. Global Science and Technology., v. 03, n. 01 p.19 - 29, jan/abr. 2010. Último acesso: 08/04/2015.

VICHI F. M. e MANSOR, M. T. C. Energia, meio ambiente e economia: o Brasil no contexto mundial. Química Nova, v. 32, n. 3, p. 757-767, 2009. Último acesso: 08/04/2015.

MASCARENHAS, L.M.A. et al. Sensoriamento Remoto como Instrumento de Controle e Proteção Ambiental: Análise da Cobertura Vegetal Remanescente na Bacia do Rio Araguaia. Sociedade \& Natureza, Uberlândia, v. 21, n. 1, p. 5-18, abril de 2009. Último acesso: 08/04/2015.

MATTOS, A.D.M. et al. Valoração Ambiental de Áreas de Preservação Permanente da Microbacia do Ribeirão São Bartolomeu no Município de Viçosa, MG. Revista Árvore, Viçosa-MG, v. 31, n. 2, p. 347-353 de 2007. Último acesso: 08/04/2015.

VOIGT, S. et al. Satellite Image Analysis for Disaster and Crisis-Management Support. IEEE Transactions on Geoscience and Remote Sensing, v. 45, n. 6, junho de 2007. Último acesso: 09/04/2015.

PINTO, L.V.A. et al. Caracterização Física da Bacia Hidrográfica do Ribeirão Santa Cruz, Lavras, MG e Uso Conflitante da Terra em Suas Áreas de Preservação Permanente. Cerne, Lavras, v. 11, n. 1, p. 49-60, jan./mar de 2005 . Último acesso: $10 / 04 / 2015$.

MONTEBELO. L. A. et al. Relação entre uso e cobertura do solo e risco de erosão nas áreas de preservação permanente na bacia do ribeirão dos Marins, Piracicaba-SP. Anais XII Simpósio Brasileiro de Sensoriamento Remoto, Goiânia, Brasil, 16-21 de abril de 2005, INPE, p. 3829-3836. Último acesso: 10/04/2015. 